\title{
Polymerase chain reaction amplification and restriction enzyme typing as an accurate and simple way to detect and identify human papillomaviruses
}

\author{
S. PIZZIGHELLA*, M. RASSU, I. PIACENTINI*, B. MASCHERA and G. PALÚ \\ Institute of Microbiology, University of Padua Medical School, Padua and * Microbiology Department, OCM Verona, \\ Italy
}

\begin{abstract}
Summary. A simple and economic method for the detection and identification of human papillomaviruses (HPV) is described. The method has been developed with cloned HPV DNA and DNA from clinical samples. Genomic fragments were obtained from several different HPV types, including the ones most frequently encountered in the genital tract by polymerase chain reaction (PCR) amplification directed by degenerate general primers. The amplification fragments were identified by a form of miniature fingerprinting, with a set of restriction enzymes that gave a unique digestion pattern for each HPV type. Different strategies are proposed, based on PCR and restriction analysis, and this approach to identification was compared with more classic methods such as Southern hybridisation.
\end{abstract}

\section{Introduction}

The oncogenic properties of papillomaviruses were first demonstrated in animal models and in 'in-vitro' experiments. Clinical and epidemiological studies established strong correlations between genital and anal cancers and papillomavirus (HPV) infection in man. ${ }^{1}$ Epithelial neoplasia, other than anogenital cancer, has also been related to HPV infection. ${ }^{2-6}$ Various HPVs have been identified that usually infect the genital tract. They can be divided into two groups: those (HPV-6 and HPV-11) which are associated with nonmalignant lesions, such as condylomata, and are thought not to play an aetiological role in neoplasia $;^{7,8}$ and those which are found in neoplastic lesions. Among the latter, HPV-16 and HPV-18 are the most frequently isolated, but $\mathrm{HPV}-31,{ }^{8} \mathrm{HPV}-33,{ }^{9} \mathrm{HPV}-$ $35,{ }^{10} \mathrm{HPV}-52 \mathrm{~b},{ }^{11} \mathrm{HPV}-58^{12}$ and possibly other types ${ }^{13}$ are also involved.

Although different chemicals and infectious agents have been ranked among the pathogenetic factors of cervical cancer-including byproducts of tobacco smoking, ${ }^{14}$ oral contraceptives, ${ }^{15}$ herpes simplex virus, ${ }^{16}$ cytomegalovirus and Epstein-Barr virus, ${ }^{17}$ HPV infection has been strongly linked to both cellular transformation $^{18}$ and maintenance of the malignant phenotype. HPV DNA can be detected in virtually all patients with genital cancer, ${ }^{19}$ even if no data are available to assess how long the infection might have preceded development of neoplasia. Assuming that infection by HPV is a necessary event in the process of

Received 2 Oct. 1992; accepted 29 Nov. 1992.

† Correspondence should be sent to Professor G. Palú. neoplastic transformation, it could be expected that HPV would be found in cervical tissue well before any other cytopathological change or clinical finding could alert the clinician. The ability to find "oncogenic" HPVs in healthy patients could be very useful in identifying a subpopulation of women at risk of developing cancer, for whom more careful clinical surveillance is needed. Indeed, a significant percentage of women who carry "oncogenic" HPVs (10-20\% in different reports), ${ }^{20,21}$ have a higher relative risk of developing cancer than the non-infected population. ${ }^{1}$

It is clear that, for diagnostic purposes, it is necessary to devise a system that is sensitive enough to allow the detection of HPVs very early in the disease. In this respect, DNA amplification by polymerase chain reaction (PCR) appears to be the technique of choice to reveal minimal amounts of HPV DNA. ${ }^{22-24}$

We have developed a simple and cheap method of detecting and typing HPVs in which a single pair of degenerate consensus primers enable the amplification of genomic sequences from at least six different HPVs. Typing is done by restriction enzyme digestion of the PCR product. The effectiveness of this approach has been assessed with cloned HPV DNA and DNA from clinical samples.

\section{Materials and methods}

Plasmids containing complete HPV genomes were propagated in Escherichia coli strain HB 101, supE44 hsdS20 $\left(\mathrm{r}_{\mathrm{B}}^{-} \mathrm{m}^{-}{ }_{\mathrm{B}}\right)$ recA13 ara-14 proA2 lacY1 galK2 rpsL20 xyl-5 mtl-1, and purified by conventional techniques. ${ }^{25}$ DNA was also extracted from paraffin- 
Table. Expected size of fragments after digestion of HPVspecific PCR products by restriction endonucleases

\begin{tabular}{lccccccc}
\hline & \multicolumn{6}{c}{$\begin{array}{c}\text { Sizes of fragments (bp) expected } \\
\text { in products from HPV }\end{array}$} \\
\cline { 2 - 7 } Amplified DNA & -6 & -11 & -16 & -18 & -31 & -33 \\
\hline Total length & 654 & 654 & 648 & 538 & 645 & 649 \\
Digestion fragments & & & & & & \\
AccI & 643 & 654 & 386 & 359 & 282 & 405 \\
& 11 & - & 146 & 179 & 251 & 244 \\
TaqI & - & - & 116 & - & 112 & - \\
HincII & 536 & 654 & 648 & 504 & 645 & 649 \\
SspI & 118 & - & -- & 34 & - & - \\
& 654 & 654 & 648 & 538 & 370 & 518 \\
NdeI & - & - & - & - & 275 & 131 \\
HinfI & 388 & 469 & 458 & 538 & 538 & 326 \\
& 266 & 185 & 107 & - & 107 & 188 \\
& - & - & 83 & - & - & 135 \\
& 494 & 494 & 648 & 538 & 645 & 649 \\
& 160 & 160 & - & - & - & - \\
& 419 & 419 & 538 & 538 & 410 & 389 \\
& 181 & 235 & 110 & - & 189 & 260 \\
& 54 & - & - & - & 46 & - \\
\hline
\end{tabular}

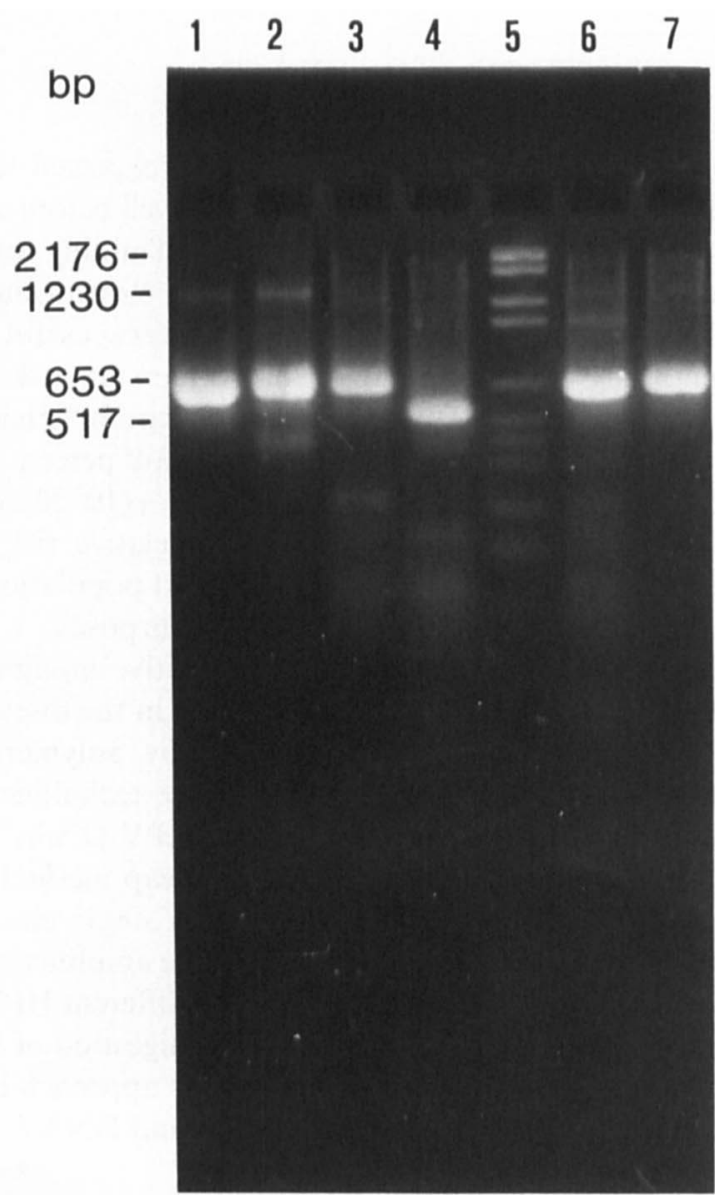

Fig. 1. PCR amplification of cloned HPV DNA by general primers. Lane 1, HPV-6; 2, HPV-11; 3, HPV-16; 4, HPV-18; 5, mol. wt markers; 6, HPV-31; 7, HPV-33.

embedded samples of codylomata obtained for histopathological examination. The extraction technique was essentially that described by Wright and Manos ${ }^{26}$ with two octane and two ethanol extraction cycles and extensive proteinase $\mathrm{K}$ digestion.
Nucleotide sequence analysis

Genomic sequences of the different HPVs were obtained by EMBL data bank and analysed for the presence of homologies and restriction sites by the Microgenie (Beckman) program.

\section{Primer synthesis}

Primers were synthesised with a Beckman synthesiser (DNA SM model) and purified by high performance liquid chromatography (HPLC). Throughout the study, degenerate consensus primers designed by Evander and Wadell were used ${ }^{24}$ these could direct the amplification of DNA from several different HPVs, including the six types found most frequently in the genital tract-HPV-6, 11, 16, 18, 31 and 33. Computer analysis showed that these primers should be able to amplify sequences of HPV-35 too, ${ }^{27}$ but this was not tested. The amplified fragment is localised in the E7-E1 genomic region of all viruses, encompassing nucleotides 607-1260 for HPV-6 and -11, nucleotides 636-1283 for HPV-16, nucleotides 805-1342 for HPV-18, nucleotides 634-1278 for HPV31 , and nucleotides $647-1295$ for HPV-33. The size of fragments varied from 645 bp to 654 bp for all viruses tested except for HPV-18, in which a 538-bp product was obtained that represents a useful marker for typing.

\section{PCR}

For amplification, $10-100 \mathrm{pg}$ of recombinant DNA or $0 \cdot 1-1 \mu \mathrm{g}$ of DNA extracted from clinical samples, were mixed with a solution of dATP, dTTP, dCTP and dGTP (final concentration $50 \mathrm{mM}$ each) in PCR buffer (10 mM Tris- $\mathrm{HCl}, \mathrm{pH} 8.3 ; 50 \mathrm{mM} \mathrm{KCl} ; 1.5 \mathrm{mM} \mathrm{MgCl}_{2}$; gelatin $100 \mu \mathrm{g} / \mathrm{ml}$ ), containing 24 pmols of each primer and $2 \mathrm{U}$ of Taq polymerase, in a final volume of $100 \mu \mathrm{l}$. The mixture was overlaid with $100 \mu \mathrm{l}$ of paraffin oil and subjected to $30-40$ cycles of amplification. Each cycle included denaturation at $94^{\circ} \mathrm{C}$, annealing at $50^{\circ} \mathrm{C}$ and elongation at $72^{\circ} \mathrm{C}$, $1 \mathrm{~min} / \mathrm{step}$. At the end of these cycles there was an additional extention step of $10 \mathrm{~min}$ at $72^{\circ} \mathrm{C}$. Negative controls with pBR322 were included in each run.

\section{Detection and identification of PCR product}

After amplification, a 20- $\mu$ l sample was digested with several restriction enzymes-AccI, TaqI, HincII, $S s p I, N d e I$ and HinfI; the predicted sizes of the digestion fragments are shown in the table. Digested fragments were loaded on to a NuSieve agarose $3 \%$ gel (FMC Bioproducts), electrophoresed in TBE buffer (0.045 M Tris-borate, 0.001 M EDTA), stained with ethidium bromide and photographed under UV illumination with a Polaroid MP-4 Land Camera. Restriction enzyme analysis was also performed in the 


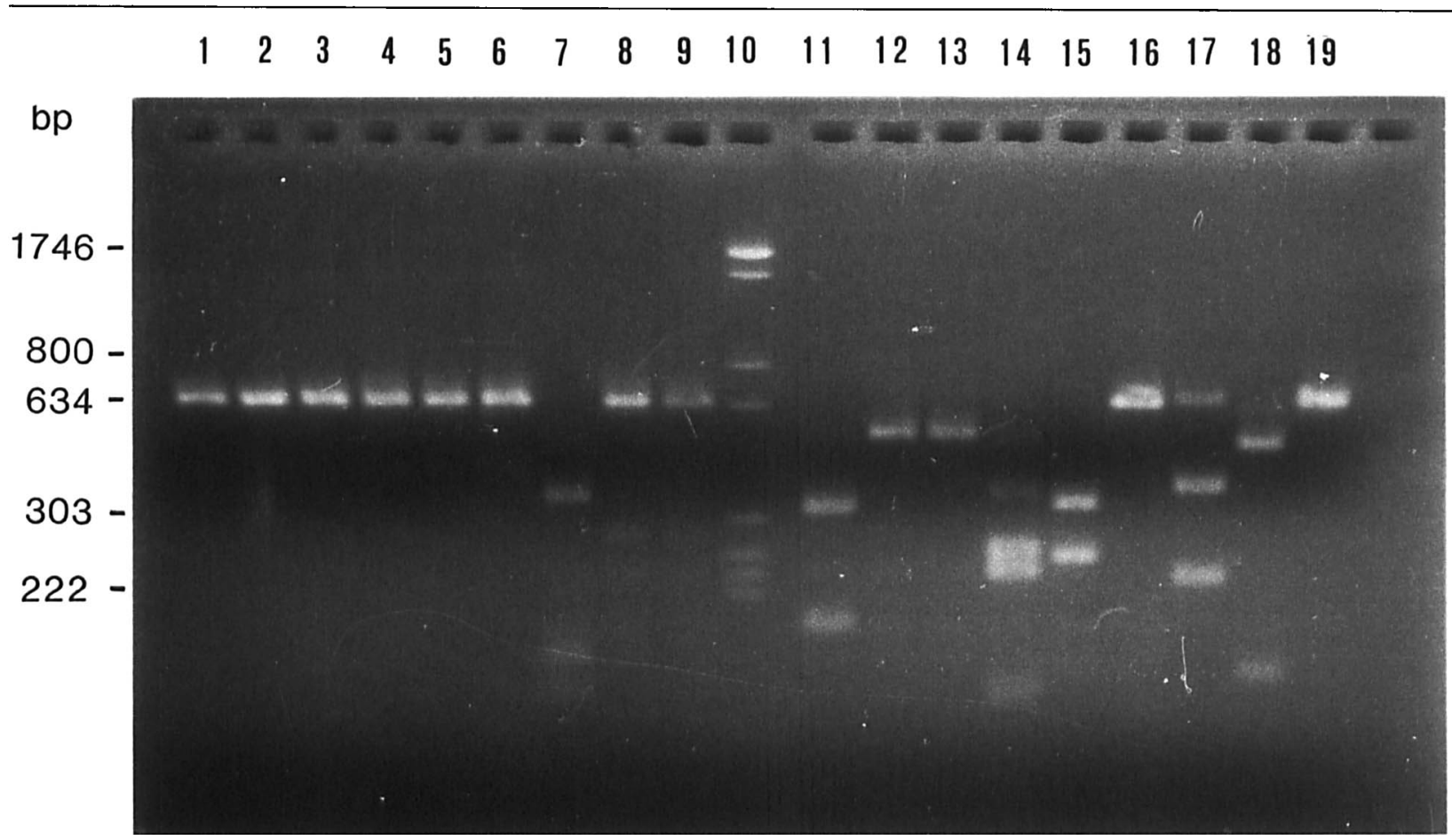

Fig. 2. Restriction endonuclease analysis of amplification fragments shown in fig. 1 with $A c c$ I and HincII. Lane 1, HPV-6, AccI; 2, HPV-6, HincII; 3, HPV-6 uncut control; 4, HPV-11, AccI; 5, HPV-11, HincII; 6, HPV-11 uncut control; 7, HPV-16, AccI; 8, HPV-16, HinclI; 9, HPV-16 uncut control; 10, mol. wt markers; 11, HPV-18, AccI; 12, HPV-18, HincII; 13, HPV-18 uncut control; 14, HPV-31, AccI; 15, HPV31, HincII; 16, HPV-31 uncut control; 17, HPV-33, AccI; 18, HPV-33, HincII; 19, HPV-33 uncut control.

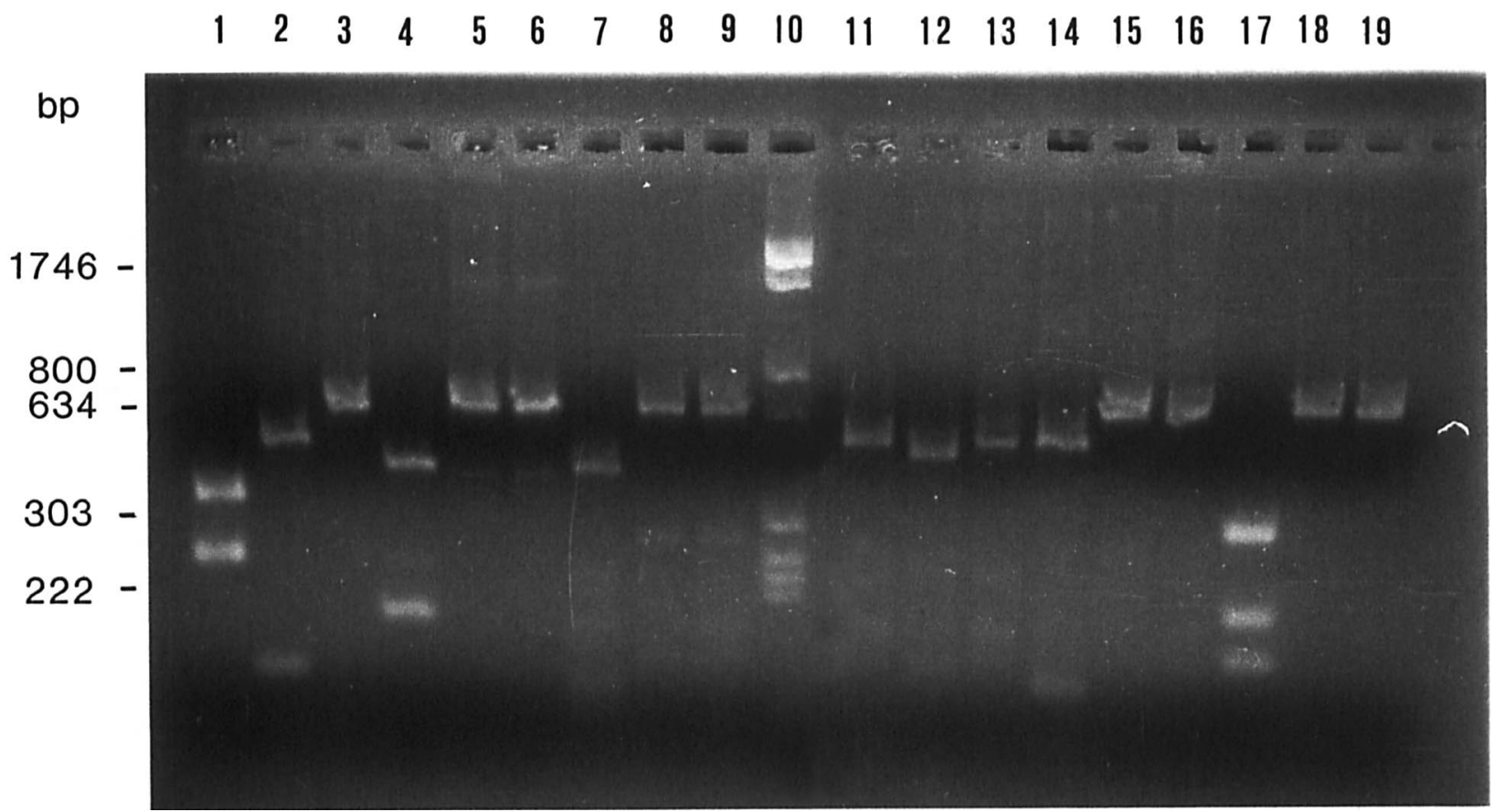

Fig. 3. Restriction endonuclease analysis of amplification fragments shown in fig. 1 with $S s p \mathrm{I}$ and TaqI. Lane 1, HPV-6, SspI ; 2, HPV-6, TaqI; 3, HPV-6 uncut control; 4, HPV-11, SspI; 5, HPV-11, TaqI ; 6, HPV-11 uncut control; 7, HPV-16, SspI; 8, HPV-16, TaqI; 9, HPV-16 uncut control; 10, mol. wt markers; 11, HPV-18, SspI; 12, HPV-18, TaqI; 13, HPV-18 uncut control; 14, HPV-31, SspI; 15, HPV-31, TaqI; 16, HPV-31 uncut control; 17, HPV-33, SspI; 18, HPV-33, TaqI; 19, HPV-33 uncut control.

case of HPV-18, although the specific amplification fragment could be identified by its lower mol. wt.

\section{Results}

The restriction enzymes that were selected are reported in the table, together with the sizes of the fragments generated and the respective attribution to each HPV genotype. It is readily apparent that the use of one or more enzymes can lead to an accurate identification of the PCR product.

The degenerate consensus primers used in this study were able to direct the amplification of DNA from all six HPCVs tested, giving a band of the expected size after gel electrophoresis (fig. 1). The assay sensitivity was of the order of $10 \mathrm{fg}$ of template DNA for five of the six HPVs tested-HPV-6, 11, 16, 18 and 33. Amplification efficiency in the case of HPV-31 was 


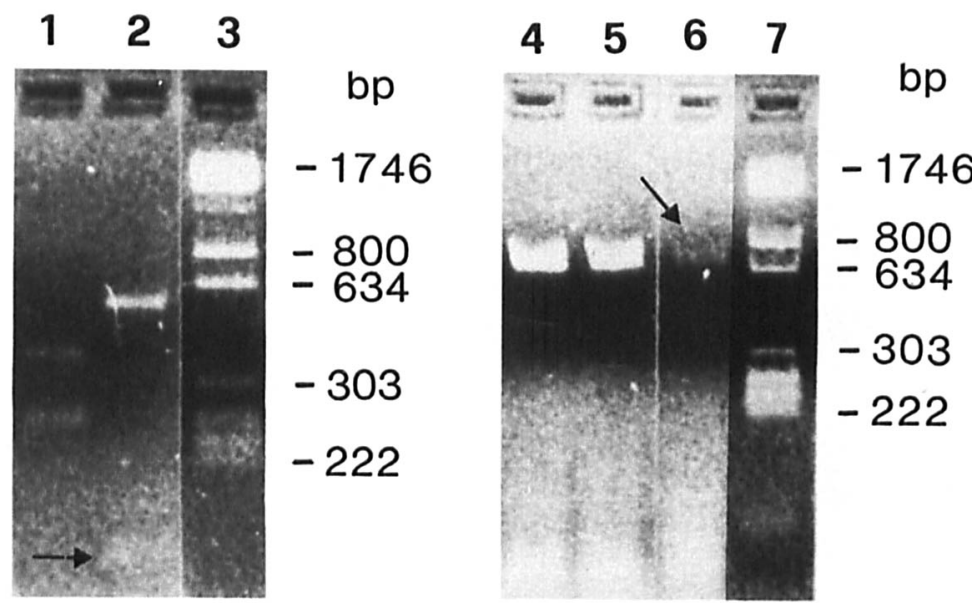

Fig. 4. PCR amplification and restriction enzyme typing of HPV from human condylomata. Lane 1, sample 1, SspI ; 2, sample 2, TaqI ( $\rightarrow$ : $118 \mathrm{bp}) ; 3$, mol. wt markers; 4 , sample $1 ; 5$, sample $2 ; 6$, sample $3(\rightarrow): 7$, mol. wt markers.

somewhat lower, a result which is consistent with the presence of three mismatches in the central region of the sense primer. $^{24}$ The specificity of the detected products was tested by restriction enzymes. Results are shown in figs. 2 and 3. Restriction enzymes gave fragments of the expected size, demonstrating that the amplified DNA was specific for the different HPVs. It is also noticeable (fig. 2) that $A c c$ I produced more bands than expected (lanes 11, 14 and 17), due to a partial digestion of the amplification product by this enzyme. As shown in lane 11, HPV-18 was cut at position 983 , giving two bands of 359 and $179 \mathrm{bp}$, plus the original uncut segment of $538 \mathrm{bp}$. The same also holds true for HPV-33 (lane 17), which was only partially digested at position 1051. For HPV-31, the pattern is more complicated; the PCR fragment was cut at positions 745 and 1027, giving three bands of 112,282 and $251 \mathrm{bp}$, which are shown clearly in lane 14. The two additional bands that are significant, one of $533 \mathrm{bp}$ and the other of $394 \mathrm{bp}$, were generated by $A c c$ I digestion only at position 745 and 1027 respectively. In another set of experiments, when a new batch of $A c c I$ was used with the same substrate DNA, a complete pattern of digestion was observed (not shown). Further analysis with NdeI and HinfI gave fragments of the expected sizes. Spurious, very faint bands of low mol. wt can be seen only occasionally (lane 8, fig. 2; lanes 5 and 6, fig. 3). This result, which may be due to either contamination or mis-priming, did not affect detection and, consequently, the specificity of the assay.

A few clinical specimens were studied by the approach described above. In fig. 4 , an analysis of three condylomata is shown. Clearly visible bands were obtained with samples 1 and 2, whereas only a low intensity band was observed with sample 3 . Restriction digestion of the PCR products 1 and 2, with $S s p \mathrm{I}$ and $T a q \mathrm{I}$ respectively, gave a pattern typical of HPV-6b. The band generated from sample 3 was too faint to be analysed by restriction endonuclease digestion.

\section{Discussion}

A method is described for the detection and typing of HPVs which could be very useful for clinical purposes, because it is simple and economic. Taking advantage of the sequence homology between different HPV types, several authors have proposed the use of general primers for their simultaneous detection. ${ }^{24,28,29}$ This approach seems more convenient than using specific primers for each $\mathrm{HPV}^{23}$ or a mixture of such primers in a single tube. ${ }^{30}$

In this study, a set of general primers already described by Evander and Wadell was employed ${ }^{24}$ these are complementary to sequences spanning the E1-E7 region of HPV genomes. This region is highly conserved among different genotypes and is not usually affected by integration into cellular DNA. Unlike the previous authors, who checked the specificity of the amplified products by Southern blot hybridisation, we exploited selective sequence recognition by restriction endonucleases. The amplified DNA was digested by several different endonucleases to assign it to a specific HPV genotype. Only in the case of $A c c I$ were some drawbacks encountered, such as the presence of extra-numerary bands in some experiments. However, these bands clearly represented partial digestion products and are shown here to demonstrate that identification was not affected, if the molecular complexity of the generated fragments was carefully checked. The restriction digestion profiles showed that the amplification bands visualised by ethidium bromide staining were specific for each HPV type.

The use of Southern blotting, followed by hybridisation with specific probes, is a very effective procedure for the detection and identification of amplified sequences. However, although it is more sensitive than ethidium bromide staining, it is not practical for the routine examination of a large number of clinical samples. Restriction typing, such as the one described here, is, at least in theory, more specific than hy- 
bridisation probing, either with Southern or dot blot which depend critically upon the stringency conditions used in the experiment. Further problems can arise from false positive hybridisation signals caused by partial identity between the probe and the amplified DNA. When working with HPVs, such an event is not at all rare, because of the high degree of sequence homology shared by many HPV genotypes. Restriction typing has other advantages; being easy to perform and adaptable, it can provide the clinician with a large body of information, e.g., by using either $N d e \mathrm{I}$ or $A c c \mathrm{I}$, "oncogenic" and "non-oncogenic" HPVs can readily be distinguished, a feature which is already clinically relevant. Alternatively, it is possible to type within "oncogenic" HPVs with $A c c \mathrm{I}$, and also to discriminate between HPV-6 and HPV-11 (TaqI). Finally, all six HPVs tested can be simultaneously typed with a single enzyme ( $S s p I$, table).

This approach, of PCR amplification followed by restriction endonuclease typing, could be very useful, provided that enough amplified DNA is produced. Our results with clinical samples have demonstrated the effectiveness and specificity of the method when the amplification product is clearly detected by ethidium bromide staining. A higher sensitivity is warranted when working with clinical samples containing just a few cells with a low copy number of HPV genomes. Different general primers, eventually coupled in a nested PCR, ${ }^{21}$ could solve this problem.

It has to be emphasised that HPV-16 and -18 are the HPVs most frequently associated with genital carcinoma; therefore, their detection should be the primary goal of any method devised to reveal and type HPV.

Cloned HPV $-6,-11,-16$ and -18 were kindly provided by Professor H. zur Hausen. Plasmids containing the genomes of HPV-31 and -33 were a gift from Professor E. Cassai and Dr G. Pozzi. This work was supported by I.S.S. 7204-84 grant C.N.R. and M.P.I. grants.

\section{References}

1. zur Hausen H. Papillomaviruses as carcinomaviruses. In: Klein $\mathrm{G}$ (ed) Advances in viral oncology. New York, Raven Press. 1989: 1-26.

2. Grimmel M, de Villiers E-M, Pawlita M, Neumann C, zur Hausen $\mathrm{H}$. Characterization of a new human papilloma virus type (HPV-41) isolated from disseminated warts and the detection of closely related sequences in some squamous cell carcinomas. Int $J$ Cancer 1988; 441 : 5-9.

3. Loning T, Ikenberg H, Becker J, Gissmann L, Hoepfner I, zur Hausen $H$. Analysis of oral papillomas, leukoplasias and invasive carcinomas for human papillomavirus type related DNA. J Invest Dermatol 1985; 84: 417-420.

4. de Villiers E-M, Weidaner $M$, Otto $H$, zur Hausen $H$. Papillomavirus DNA in human tongue carcinomas. Int $J$ Cancer 1985; 36: 575-578.

5. Kahn T, Schwartz E, zur Hausen $H$. Molecular cloning and characterization of the DNA of a new human papillamavirus (HPV-30) from a laryngeal carcinoma. Int $J$ Cancer $1986 ; 37: 61-65$.

6. Byrne JC, Tsao MS, Fraser RS, Houley PM. Human papillomavirus 11 in a patient with chronic laringotracheobronchial papillomatosis and metastatic squamous cell carcinoma of the lung. $N$ Engl J Med 1987; 317: 873-878.

7. Wright TC, Richart RM. Role of human papillomavirus in the pathogenesis of genital tract warts and cancer. Gynecol Onc 1990; 37: 11-164.

8. Lorincz AT, Temple GF, Kurman RJ, Jenson AB, Lancaster WD. Oncogenic association of specific human papillomavirus types with cervical neoplasia. J Natl Can Inst 1987; 79: 671-677.

9. Beaudenon S, Krempsorf D, Croissant O, Jablonska S, Wainhobson S, Orth G. A novel type of human papillomavirus associated with genital neoplasia. Nature 1986; 321 : 246-249.

10. Lorincz AT, Quinn AP, Lancaster WD, Temple GF. A new type of papilloma virus associated with the uterine cervix. Virology 1987; 159: 187-190.

11. Shimoda K, Lorincz AT, Temple GF, Lancaster WD. Human papillomavirus type 52: a new virus associated with cervical neoplasia. J Gen Virol 1988; 69: 2925-2928.

12. Matsukura T, Sugase M. Molecular cloning of a novel papillomavirus (type 58) from an invasive cervical carcinoma. Virology 1990; 833-836.

13. de Villiers E-M. Heterogeneity of the human papillomavirus group. J Virol $1989 ; 4898-4903$.

14. Layde PM, Broste SK. Carcinoma of the cervix and smoking. Biomed Pharmacother 1989; 43: 161-165.

15. Vessey N, Grica D. Carcinoma of the cervix and oral contraceptives: epidemiological studies. Biomed Pharmacother 1989; 43: 157-160.

16. Nahmias AJ, Sawanabori S. The genital herpes-cervical cancer hypothesis-ten years later. Prog Exp Tumor Res 1978; 21 : 177.

17. Stevenson K, Macnab JCM. Cervical carcinoma and human cytomegalovirus. Biomed Pharmacother 1989; 3: 173-176.

18. Phelps WC, Yee CL, Munger K, Howley PM. The human papilloma virus type $16 \mathrm{E} 7$ gene encodes transactivation and transformation functions similar to adenovirus ElA. Cell 1988; 53: 539-547.

19. Obalek S, Jablonka S, Orth G. HPV associated intraepithelial neoplasia of external genitalia. Clin Dermatol 1985; 3 : 104-113.

20. de Villiers E-M, Wagner D, Schneider A et al. Human papillomavirus infections in women with and without abnormal cervical cytology. Lancet 1987; 2: 703-706.

21. Evander M, Edlung K, Boden E et al. Comparison of a one-step and a two-step polymerase chain reaction with degenerate general primers in a population-based study of human papillomavirus infection in young Swedish women. $J$ Clin Microbiol 1992; 30: 987-992.

22. Gregoire L, Arella M, Campione-Piccardo J, Lancaster WD. Amplification of human papillomavirus DNA sequences by using conserved primers. J Clin Microbiol 1989; 27: 2660-2665.

23. van den Brule AJC, Meijer CJLM, Bakels V, Kenemans P, Walboomers JMM. Rapid detection of human papillomavirus in cervical scrapes by combined general primer-mediated and type-specific polymerase chain reaction. J Clin Microbiol 1990; 28: 2739-2743.

24. Evander M, Wadell G. A general primer pair for amplification and detection of genital human papillomavirus types. $J$ Virol Methods 1990; 31: 239-250.

25. Maniatis T, Fritsch EF, Sambrook J. Molecular cloning: a laboratory manual, 2nd edn. Cold Spring Harbor, New York, Cold Spring Harbor Laboratory. 1989.

26. Wright DK, Manos MM. Sample preparation from paraffinembedded tissues. In: Innis MA, Gelfand DH, Sninsky JJ, White TJ (eds) PCR protocol. A guide to methods and applications. Academic Press, Inc. 1990: 153-158.

27. Marich JE, Pontsler AV, Rice SM, McGraw KA, Dubenski TW. The phylogenetic relationship and complete nucleotide sequence of human papillomavirus type 35 . Virology 1992; 186: 770-776.

28. Fujinaga Y, Shimada M, Okazawa K, Fukushima M, Kato I, 
Fujinaga K. Simultaneous detection and typing of genital human papillomavirus DNA using the polymerase chain reaction. J Gen Virol 1991; 72: 1039-1044.

29. Snijders PJF, Meijer CJLM, Walboomers JMM. Degenerate primers based on highly conserved regions of aminoacid sequence in papillomaviruses can be used in a generalized polymerase chain reaction to detect productive human papillomavirus infection. J Gen Virol 1991; 72: 2781-2786.

30. Anceschi MM, Falcinelli C, Pieretti M, Cosmi EV. Multiple primer pairs polymerase chain reaction for the detection of human papillomavirus types. J Virol Methods 1990; 28: 59-66. 